\title{
Shockable Rhythm at Hospital Arrival as the Predictor of Favourable Neurological Outcome in Patients with Out-of-Hospital Cardiac Arrest (OHCA) Receiving Extracorporeal Cardiopulmonary Resuscitation (ECPR)
}

Pei-I Su

National Taiwan University Hospital

Min-Shan Tsai

National Taiwan University Hospital

Wei-Ting Chen

National Taiwan University Hospital

Chih-Hung Wang

National Taiwan University Hospital

Wei-Tien Chang

National Taiwan University Hospital

Matthew Huei-Ming

National Taiwan University Hospital

Wen-Jone Chen

National Taiwan University Hospital

Chien-Hua Huang ( $\triangle$ chhuang5940@ntu.edu.tw)

National Taiwan University Hospital

\section{Research}

Keywords: Extracorporeal cardiopulmonary resuscitation (ECPR), Out-of-hospital cardiac arrest (OHCA), Shockable rhythm at the time of hospital arrival.

Posted Date: October 29th, 2021

DOl: https://doi.org/10.21203/rs.3.rs-965055/v1

License: (c) (i) This work is licensed under a Creative Commons Attribution 4.0 International License.

Read Full License 


\section{Abstract}

Introduction: For patients with out-of-hospital cardiac arrest (OHCA) without return of spontaneous circulation under advanced life support, extracorporeal cardiopulmonary resuscitation (ECPR) is the only lifesaving option. This study aimed to analyse the predictors of favourable neurological outcomes (FO, cerebral performance category 1-2) at hospital discharge among patients with OHCA following ECPR.

Methods: In this single-centre retrospective study, 126 patients with OHCA who received ECPR between January 2012 and December 2019 were enrolled. The primary outcome was the FO at hospital discharge. The predictors of FO were assessed using multiple logistic regression analysis. Patients with an initial shockable rhythm were further analysed according to the cardiac rhythm at the time of hospital arrival.

Results: Among the patients who received ECPR, the FO at hospital discharge was $21 \%$. Certain resuscitation variables were associated with $F O$ including witnessed collapse $(P=0.014)$, bystander CPR $(P=0.05)$, shorter no-flow time $(P=0.008)$, and a shockable rhythm at hospital arrival $(P=0.009)$. Multiple logistic regression showed that a shockable rhythm at hospital arrival was the only independent predictor of FO at discharge (odds ratio, 3.012; $95 \%$ confidence interval, $1.06-8.53 ; \mathrm{P}=0.038$ ). Among patients with an initial shockable rhythm, the group with a shockable rhythm at hospital arrival had a FO of $30 \%$, which was significantly higher than the $11 \%$ in the non-shockable rhythm group $(P=0.043)$.

Conclusions: In patients with OHCA who received ECPR, a shockable rhythm at the time of hospital arrival was associated with favourable neurological outcomes at discharge. The ECPR selection criteria could consider the rhythm at hospital arrival.

\section{Introduction}

The annual incidence of out-of-hospital cardiac arrest (OHCA) is estimated to be between 30 and 97 individuals per 100,000 persons worldwide. ${ }^{1-3}$ The overall survival-to-discharge rate is $8.8 \%$, highest in Europe (11.7\%) and lowest in Asia (4.5\%). ${ }^{4}$ Cardiac origin (e.g. acute myocardial infarction and fatal arrhythmia) as the cause of OHCA have been reported to be related to higher chances of survival and favourable neurological outcome. ${ }^{5-8}$ Despite advances in medical treatment and public health care systems, the survival rate of SCD remained around $5-10 \% .{ }^{12,13}$ For patients with cardiac causes of OHCA who fail to reach return of spontaneous circulation under standard advanced cardiac life support, implementation of venoarterial extracorporeal membrane oxygenation (VA-ECMO) is the only remaining lifesaving chance. ${ }^{14-20}$ However, extracorporeal cardiopulmonary resuscitation (ECPR) is extremely invasive and demands tremendous medical resources. Based on a previous study on cost-effectiveness, the mean cost of ECPR is approximately 40,000 USD per patient. ${ }^{21}$ Therefore, it is important to select patients who would benefit from ECMO implementation. The 2020 American Heart Association (AHA) Guidelines for Cardiopulmonary Resuscitation recommended the prudent selection of ECPR in patients with OHCA who have reversible cardiac arrest cause. However, the selection criteria remain unclear, and more evidence is warranted. ${ }^{22}$ In those who survived ECPR, good functional neurological status was the 
most important outcome. Therefore, this study aimed to analyse the neurological outcomes of ECPR in our hospital and investigate the predictors of favourable neurological outcomes.

\section{Methods}

\section{Study population}

The inclusion criteria were patients aged 18 years or older, who had OHCA, and were treated with ECPR. Patients who met the following criteria were excluded: 1) ECPR was initiated at another hospital and the patient was transferred after ECMO implementation, 2) in-hospital cardiac arrest (IHCA), 3) traumatic OHCA, and 4) OHCA with sustained ROSC (ROSC for more than20 minutes) but ECMO support warranted for hemodynamic support.

\section{Study setting, ECPR inclusion criteria, and ECMO procedure}

This retrospective study was conducted from January 2012 to December 2019 in a tertiary hospital in Taipei city, with an emergency department with more than 11,5000 visits annually and 220 intensive care unit (ICU) beds. This hospital is an academic medical centre and a referral hospital for Taipei City and New Taipei City, covering a population of five million. The requirement for informed consent was waived because of the retrospective nature of the study.

The ECPR bundle care in NTUH was as follows. ${ }^{23,24}$ Patients with OHCA were transferred to the resuscitation area of the emergency department (ED). If they did not achieve ROSC after 10 minutes of standard ACLS, the treating emergency physician would discuss with the duty cardiovascular surgeon for ECPR eligibility. Patients were considered eligible for ECPR if they met all the following criteria: (1) age < 80 years, (2) witnessed collapse with bystander CPR, (3) pre-disease cerebral performance category (CPC) score 1-2 and no terminal malignancy; and (4) presumed cardiac origin as the cause. The cardiovascular surgeon had a final decision on ECMO eligibility.

The ECMO components in NTUH included a centrifugal pump and an oxygenator (Medtronic, Anaheim, CA; Medos, Stolberg, Germany; and Maquet, Rastatt, Germany). After ECMO insertion, the patient underwent computed tomography to survey possible OHCA causes, and the duty cardiologist evaluated the feasibility of coronary angiography. Finally, the patient was admitted to the ICU for post-resuscitation care.

\section{Data collection}

Baseline characteristics and comorbidities were recorded in the admission records and were retrospectively collected. Resuscitation variables were collected from emergency medical service (EMS) records and medical records in the ED. Initial rhythm was defined as the first recorded rhythm 1) by the EMS staff at the scene for the patients transported by EMS service or 2) by the ED triage nurse if the patient was transported by non-medical professionals. Cardiac rhythm at hospital arrival was defined as the first recorded rhythm in the ED resuscitation area. All time intervals were retrospectively calculated 
from EMS and hospital records. Arrest-hospital time was the time interval from cardiac arrest to hospital arrival, and hospital-call ECMO time was the interval from patient arrival at the resuscitation area to the time ED physicians decided to activate ECMO. ECMO implementation time was defined as the time from the arrival of the cardiovascular surgeon to the time of complete ECMO implementation. Lactic acid and blood $\mathrm{pH}$ values were recorded from the first blood sampling on hospital arrival, whether from arterial or venous blood. The intervention after ECPR and neurological outcomes at discharge were collected from medical records.

\section{Outcome}

The primary outcome was a favourable neurological outcome at discharge, defined as a CPC score of 1 or 2. Patients with an initial shockable rhythm were further separated according to the cardiac rhythm at hospital arrival. The relationship between cardiac rhythm at hospital arrival and FO was evaluated.

\section{Statistics}

Categorical variables are expressed as percentages and compared using the chi-square test. Continuous variables were expressed as mean \pm standard deviation, and t-tests were used to delineate differences. All variables with $P$ values 0.15 were included in multiple logistic regression analyses to determine the independent variables for predicting favourable neurological outcomes at discharge. Statistical significance was set at $\mathrm{P}<0.05$. All computations were performed using SPSS, version 16.0 (IBM Corp., Armonk, NY, USA).

\section{Results}

\section{Patient enrolment}

From January 2012 to September 2019, a total of 594 patients with cardiac arrest who received ECPR were admitted to the ICU. We excluded 55 patients because ECPR was initiated at another hospital, and detailed resuscitation variables were lacking. Another eight traumatic causes were excluded (one drowning, three airway obstructions, 3 inhalation injuries, 1 suicidal attempt with muscle relaxant injection). We also excluded 405 patients with IHCA. The remaining 126 patients were included in this study (Figure 1).

\section{Patient characteristics and outcome}

Baseline characteristics and resuscitation variables are provided in Table 1. The median age was 55 years, and $107(85 \%)$ patients were men. A total of $92(68 \%)$ patients had cardiac origin as the cause: 83 (62\%) patients had acute coronary syndrome, 7 (5\%) patients had fatal arrhythmia and/or cardiomyopathy, and $2(1 \%)$ patients had acute myocarditis. None of the patients had terminal malignancy, severe cognitive impairment, or end-stage liver disease before cardiac arrest. A total of 107 (85\%) patients had witnessed arrest, and 88 (70\%) patients received bystander CPR; 94 (75\%) patients had an initial shockable rhythm (ventricular fibrillation/pulseless ventricular tachycardia), and 70 (56\%) 
patients had shockable rhythm at hospital arrival. The mean time from arrest to ECMO implementation was 60 minutes, and 18 (14\%) had non-sustained ROSC before ECPR. 
Table 1

Characteristics of study population.

\begin{tabular}{|c|c|c|c|c|}
\hline Characteristics & $\begin{array}{l}\text { All } \\
\text { patients } \\
(\mathrm{N}=126)\end{array}$ & $\begin{array}{l}\text { Favourable } \\
\text { neurological outcome } \\
(\mathrm{N}=27)\end{array}$ & $\begin{array}{l}\text { Unfavourable } \\
\text { neurological } \\
\text { outcome }(\mathrm{N}=99)\end{array}$ & $P$ value \\
\hline Age, years & $55.2 \pm 11.8$ & $54.0 \pm 11.9$ & $55.5 \pm 11.7$ & 0.55 \\
\hline Gender (male), n (\%) & $107(85)$ & $23(85)$ & $84(85)$ & 0.68 \\
\hline \multicolumn{5}{|l|}{ Comorbidities, n (\%) } \\
\hline Coronary artery disease & $41(33)$ & $7(26)$ & $34(34)$ & 0.408 \\
\hline Diabetes mellitus & $45(36)$ & $6(22)$ & $39(34)$ & 0.099 \\
\hline End stage renal disease & $6(4)$ & $1(4)$ & $5(5)$ & 0.233 \\
\hline COPD/Asthma & $6(4)$ & $1(4)$ & $5(5)$ & 0.233 \\
\hline \multicolumn{5}{|l|}{ Resuscitation variables: } \\
\hline $\begin{array}{l}\text { Witnessed collapse, } n \\
(\%)\end{array}$ & $107(85)$ & $27(100)$ & $80(81)$ & $0.014^{\star *}$ \\
\hline Bystander CPR, n (\%) & $88(70)$ & $23(85)$ & $65(66)$ & $0.05^{\star \star}$ \\
\hline No flow time, $\min$ & $3.1 \pm 4.9$ & $1.7 \pm 1.9$ & $3.5 \pm 5.3$ & $0.008 * \star$ \\
\hline Low flow time, min & $55.9 \pm 17.2$ & $52.6 \pm 13.0$ & $56.8 \pm 18.2$ & 0.266 \\
\hline Arrest-Hospital time, min & $23.1 \pm 11.7$ & $22.7 \pm 8.7$ & $24.2 \pm 16.4$ & 0.138 \\
\hline Arrest-ECMO time, min & $59.6 \pm 20.0$ & $54.3 \pm 12.9$ & $61.0 \pm 21.3$ & 0.123 \\
\hline $\mathrm{pH}$ value & $7.04 \pm 0.16$ & $7.08 \pm 0.16$ & $7.03 \pm 0.16$ & 0.244 \\
\hline Lactate level, mEq/L & $11.9 \pm 4.5$ & $11.8 \pm 5.2$ & $11.9 \pm 4.4$ & 0.952 \\
\hline $\begin{array}{l}\text { Initial shockable rhythm, } \\
\text { n (\%) }\end{array}$ & $94(75)$ & $23(85)$ & $71(71)$ & 0.154 \\
\hline $\begin{array}{l}\text { Shockable rhythm at } \\
\text { hospital, } \mathrm{n}(\%)\end{array}$ & $70(56)$ & $21(78)$ & $49(49)$ & $0.009 * \star$ \\
\hline \multicolumn{5}{|l|}{ Intervention } \\
\hline CAG, n (\%) & $92(73)$ & $27(100)$ & $65(65)$ & $<0.001^{\star \star}$ \\
\hline $\mathrm{PCl}, \mathrm{n}(\%)$ & $60(48)$ & $16(59)$ & $44(44)$ & 0.186 \\
\hline \multicolumn{5}{|c|}{ CAG: Coronary angiography, PCl: Percutaneous coronary intervention, } \\
\hline \multicolumn{5}{|c|}{ CABG: Coronary artery bypass graft, TTM: Targeted temperature management } \\
\hline ** $P$ value $<0.05$ & & & & \\
\hline
\end{tabular}




\begin{tabular}{|lllll|}
\hline Characteristics & $\begin{array}{l}\text { All } \\
\text { patients } \\
(\mathbf{N}=126)\end{array}$ & $\begin{array}{l}\text { Favourable } \\
\text { neurological outcome } \\
(\mathbf{N}=\mathbf{2 7})\end{array}$ & $\begin{array}{l}\text { Unfavourable } \\
\text { neurological } \\
\text { outcome (N=99) }\end{array}$ & P value \\
\hline CABG, $n(\%)$ & $18(14)$ & $5(18)$ & $13(13)$ & 0.386 \\
\hline TTM, $n(\%)$ & $62(49)$ & $12(44)$ & $50(50)$ & 0.577 \\
\hline $\begin{array}{l}\text { Survival to discharge, no } \\
(\%)\end{array}$ & $49(39)$ & $27(100)$ & $22(22)$ & $<0.001$ \\
\hline CAG: Coronary angiography, PCl: Percutaneous coronary intervention, & \\
\hline CABG: Coronary artery bypass graft, TTM: Targeted temperature management & \\
\hline$* *$ P value<0.05 & & & \\
\hline
\end{tabular}

The favourable neurological outcome group had a higher proportion of patients with witnessed collapse ( $100 \%$ vs. $81 \%$; $P=0.014)$, received bystander CPR ( $85 \%$ vs. $66 \% ; P=0.05)$, had a shorter no-flow time, and presented a shockable rhythm at hospital arrival ( $78 \%$ vs. $49 \% ; P=0.009)$. Notably, the initial shockable rhythm did not differ significantly between the groups ( $85 \%$ vs. $71 \%$; $P=0.154)$. More patients in the FO group underwent diagnostic coronary angiography $(100 \%$ vs. $65 \% ; \mathrm{P}<0.001)$, but the percentage of coronary intervention was similar.

\section{Neurological outcome and survival rate at hospital discharge}

Of the study population, 27 (21\%) patients had favourable neurological outcomes at hospital discharge. 49 (39\%) patients had survival to hospital discharge (including all 27 patients with CPC score of 1-2, and the other 22 patients with CPC score 3-4).

\section{Independent predictors for favourable neurological outcome}

Multiple logistic regression with variables of $\mathrm{P}$ value $<0.15$ showed that shockable rhythm at hospital arrival was the only independent predictor of favourable neurological outcome (Table 2). 
Table 2

Multiple logistic regression for favourable neurological outcome.

\begin{tabular}{|llll|}
\hline Variable & $\begin{array}{l}\text { Odds } \\
\text { ratio }\end{array}$ & $95 \%$ confidence interval & P value \\
\hline Witnessed arrest & 0.742 & $0.450-3.121$ & 0.998 \\
\hline Bystander CPR & 0.586 & $0.170-2.016$ & 0.397 \\
\hline Shockable rhythm at hospital arrival & 3.012 & $1.063-8.530$ & 0.038 \\
\hline Diabetes mellitus & 2.259 & $0.757-6.714$ & 0.144 \\
\hline Arrest-ECMO time & 0.978 & $0.170-5.623$ & 0.98 \\
\hline
\end{tabular}

\section{Influence of shockable rhythm changes on outcome}

A total of 97 patients had an initial shockable rhythm. Among them, $70(72 \%)$ patients had a shockable rhythm at hospital arrival, 12 (12\%) patients developed pulseless electrical activity (PEA), and 15 (15\%) developed asystole. (Figure 2). We studied the relationship between rhythm at the time of hospital arrival and favourable neurological outcomes among patients with an initial shockable rhythm (Table 3). We excluded 6 patients who were transported by non-medical professionals. The initial rhythm of these 6 patients was recorded by the ED triage nurse and, therefore, was the same as the hospital arrival rhythm. The shockable rhythm at hospital arrival group was more likely to have shorter arrest-hospital time, shorter ECMO insertion time, and shorter total arrest-ECMO time. Both groups had similar characteristics among age, percentage of cardiac origin, and witness collapse, and received bystander CPR and postROSC interventions (CAG, PCl, TTM). The group with a shockable rhythm at hospital arrival had $30 \% \mathrm{FO}$, which was significantly higher than the $11 \%$ in the non-shockable rhythm group ( $P=0.043, F 017 \%$ in the PEA group, and $6 \%$ in the asystole group). 
Table 3

Characteristics of patients with pre-hospital initial shockable rhythm, according to the cardiac rhythm at hospital arrival.

\begin{tabular}{|c|c|c|c|}
\hline Characteristics & $\begin{array}{l}\text { Shockable rhythm at } \\
\text { hospital arrival } \\
(\mathrm{N}=64)\end{array}$ & $\begin{array}{l}\text { Non-shockable rhythm at } \\
\text { hospital arrival } \\
(\mathrm{N}=27)\end{array}$ & $P$ value \\
\hline Age, year & $54.5 \pm 10.5$ & $51.5 \pm 13.3$ & 0.259 \\
\hline Cardiac origin, n (\%) & $53(83)$ & $20(74)$ & 0.45 \\
\hline $\begin{array}{l}\text { Acute myocardial } \\
\text { infarction, } \mathrm{n}(\%)\end{array}$ & $50(71)$ & $18(67)$ & 0.680 \\
\hline \multicolumn{4}{|l|}{ Resuscitation variables } \\
\hline Witnessed collapse, n (\%) & $57(89)$ & $20(74)$ & 0.07 \\
\hline Bystander CPR, n (\%) & $47(73)$ & $16(60)$ & 0.181 \\
\hline No flow time, min & $2.1 \pm 2.7$ & $6.2 \pm 7.8$ & $0.013^{\star \star}$ \\
\hline Low flow time, min & $55.8 \pm 13.5$ & $69.5 \pm 19.5$ & $0.013^{\star \star}$ \\
\hline Arrest-Hospital time, min & $25.1 \pm 8.4$ & $35.4 \pm 16.5$ & $0.007^{\star \star}$ \\
\hline $\begin{array}{l}\text { Hospital-Call ECMO time, } \\
\text { min }\end{array}$ & $9.7 \pm 7.9$ & $7.7 \pm 6.7$ & 0.272 \\
\hline ECMO insertion time, min & $24.8 \pm 9.2$ & $29.7 \pm 10.9$ & $0.041^{\star *}$ \\
\hline Arrest-ECMO time, min & $57.8 \pm 13.6$ & $72.1 \pm 17.3$ & $0.002^{\star \star}$ \\
\hline $\mathrm{pH}$ value & $7.03 \pm 0.13$ & $6.95 \pm 0.14$ & $0.007^{\star \star}$ \\
\hline Lactate level, mEq/L & $11.6 \pm 4.0$ & $13.5 \pm 5.6$ & 0.088 \\
\hline \multicolumn{4}{|l|}{ Intervention } \\
\hline CAG, n (\%) & $54(84)$ & $20(74)$ & 0.249 \\
\hline $\mathrm{PCl}, \mathrm{n}(\%)$ & $34(53)$ & $15(56)$ & 0.832 \\
\hline CABG, n (\%) & $10(14)$ & $3(11)$ & 0.709 \\
\hline TTM, n (\%) & $36(56)$ & $17(63)$ & 0.55 \\
\hline Outcome & & & \\
\hline
\end{tabular}

CAG: Coronary angiography, PCI: Percutaneous coronary intervention,

CABG: Coronary artery bypass graft, TTM: Targeted temperature management $\star \star P$ value $<0.05$ 


\begin{tabular}{|c|c|c|c|}
\hline Characteristics & $\begin{array}{l}\text { Shockable rhythm at } \\
\text { hospital arrival } \\
(\mathrm{N}=64)\end{array}$ & $\begin{array}{l}\text { Non-shockable rhythm at } \\
\text { hospital arrival } \\
(\mathrm{N}=27)\end{array}$ & $P$ value \\
\hline $\begin{array}{l}\text { Favourable neurological } \\
\text { outcome } \\
\text { at discharge, } \mathrm{n}(\%)\end{array}$ & $20(30)$ & $3(11)$ & $0.043^{\star *}$ \\
\hline $\begin{array}{l}\text { Survival to discharge, } \mathrm{n} \\
(\%)\end{array}$ & $30(47)$ & $9(33)$ & 0.185 \\
\hline \multicolumn{4}{|c|}{ CAG: Coronary angiography, PCI: Percutaneous coronary intervention, } \\
\hline \multicolumn{4}{|c|}{ CABG: Coronary artery bypass graft, TTM: Targeted temperature management } \\
\hline$\star * P$ value $<0.05$ & & & \\
\hline
\end{tabular}

\section{Distribution of arrest to ECMO time and shockable for outcomes}

The chances of favourable neurological outcomes decreased with prolongation of arrest to ECMO time. Figure 3 demonstrated the percentage of FO according to the duration of arrest to ECMO among patients with an initial shockable rhythm. Patients were further separated according to whether their rhythm remained shockable upon arrival at the hospital. Patients had a higher percentage of $\mathrm{FO}$ if their rhythm remained shockable at hospital arrival, with $38 \% \mathrm{FO}<45$ minutes and $32 \% \mathrm{FO}$ after $45-60$ minutes. There was still $25 \%$ FO after $60-75$ minutes for patients with a shockable rhythm at hospital arrival.

\section{Discussion}

\section{Main findings}

In this retrospective study of 126 patients with refractory OHCA treated with ECPR, $21 \%$ had favourable neurological outcomes at discharge. Shockable rhythm at hospital arrival, rather than initial shockable rhythm, predicted favourable neurological outcomes at discharge and could be used as the ECPR selection criteria in patients with OHCA.

\section{Outcome comparison}

The neurological outcome varied substantially between different studies in those with receiving ECPR because the ECPR protocol and patient selection varied between institutes. Our study reported a higher prevalence of favourable neurological outcomes than previous large population studies. ${ }^{25,26}$ Lunz et al. reported $9 \%$ of FO at 3 months follow-up in five European centres in the OHCA group. ${ }^{25}$ Compared to our study, the OHCA group in their study had a longer arrest to ECMO implementation time (75 min vs. 60 $\mathrm{min}$ ) and a lower percentage of initial shockable rhythm (59\% vs. $75 \%)$. Bougouin et al. reported a similar low favourable outcome of $6 \%$ at hospital discharge. ${ }^{26}$ The differences may also be explained by the 
longer low flow time (90 $\mathrm{min}$ ) and a much lower percentage of initial shockable rhythm (27\%) in their cohort. Therefore, our study provided a different population that may benefit from ECMO. This high percentage of FO was similar to the results of the UMN-ECPR study, which reported $33 \%$ favourable neurological outcomes at 3-month follow-up in refractory VF/pulseless VT patients. ${ }^{27}$ The characteristics of patients with shockable rhythm at hospital arrival were similar to those of the UMN-ECPR cohort in several resuscitation variables: (1) arrest to ECMO time (56 min vs. $60 \mathrm{~min}$ ), (2) bystander CPR percentage ( $74 \%$ vs. $66 \%)$, (3) blood exam pH value (7.06 vs. 7.09$)$, and (4) lactic acid level $(11.5 \mathrm{mmol} / \mathrm{L}$ vs. $11 \mathrm{mmol} / \mathrm{L})$. Initial shockable rhythm and arrest to ECMO time have been proposed as key determinants for the clinical application of ECMO. However, pre-hospital ECMO is difficult and rare in prehospital resuscitation for cardiac arrest. These patients were sent to the hospital for continuing resuscitation efforts after re-evaluation. Cardiac rhythm at hospital arrival could become important information for treatment decision-making and outcome evaluation.

\section{Shockable rhythm at hospital arrival}

Few studies have recorded and analysed cardiac rhythm at hospital arrival. Graff et al. found that $30 \%$ (97 out of 332) of patients with OHCA who had an initial shockable rhythm on the scene remained shockable at hospital arrival. They further reported that the 30-day survival rate of shockable rhythm at hospital arrival was $6 \%$, and patients with shockable rhythm at hospital arrival had a higher survival rate than those with PEA or asystole. ${ }^{28}$ Previous studies have shown that initial shockable rhythm is a predictor of favourable neurological outcomes. ${ }^{1,5-9}$ However, patients with OHCA who had an initial shockable rhythm represented a group with heterogeneous resuscitation variables, including whether they had witnessed collapse, received bystander CPR, the quality of pre-hospital CPR, the transport time to the hospital, and their physiological reservoir. In our study, we observed that $24 \%$ of patients with an initial shockable rhythm had favourable outcomes. Among them, patients who still had shockable rhythm upon arrival at the hospital had a $30 \%$ favourable outcome, compared to $17 \%$ in those with PEA at hospital arrival, and $6 \%$ in those with asystole. Patients with shockable rhythm at hospital arrival had shorter arrest-hospital time, shorter arrest-ECMO time, and less metabolic disturbance. Patients with shockable rhythm at hospital arrival may represent patients with more physiological reservoirs or receive higherquality CPR. Therefore, this group of patients could retain a structured cardiac rhythm at hospital arrival and had a higher percentage of FO and deserve aggressive management such as ECMO for resuscitation. The time point at hospital arrival could be the exact point at which physicians summarised all resuscitation variables to consider ECMO initiation. It is reasonable to consider the rhythm of hospital arrival as the ECPR selection criteria.

\section{Cardiac arrest to ECPR time}

Previous studies have also shown a negative influence of longer CPR duration on FO. The percentage of FO decreased as the flow time increased. ${ }^{27,29}$ However, whether a certain period should be used as the exclusion criterion remains unclear. Bartos et al. demonstrated from the experience of the UMN-ECPR cohort that the maximal FO percentage of ECPR was achieved within the first $30 \mathrm{~min} .{ }^{27}$ Lunz et al. used stringent ECPR criteria to retrospectively examine the mixed OHCA + IHCA ECPR cohort. They found that 
if low flow time $<60$ min was used as an inclusion criterion, FO could be further increased to above $25 \%{ }^{25}$ Wengenmayer et al. reported that the chances of survival were still $25.2 \%$ after 30 min and $9.9 \%$ after $65 \mathrm{~min}$, and recommended a decrease in the low flow time. ${ }^{29}$ Our experiences showed the same trend with $29 \%$ FO in 30-45 minutes and $<20 \%$ above 60 min. However, when using shockable rhythm at hospital arrival as selection, FO was still near $25 \%$ even when the arrest time reached 75 min. Taking the above study and our experience into consideration, combining shockable rhythm at hospital arrival could further aid the "tolerable low flow time" and increase the number of possible ECPR candidates.

\section{Limitation}

This study had several limitations, given the observational nature of the study. First, even though there were pre-specified ECPR initiation criteria in our hospital, the specific reason for initiating ECPR was based on treating physician judgement and not recorded. Some patients who may have benefited from ECPR may not have been included. Second, the time records in this study were collected from the electronic records of EMS and ED records. The exact no-flow time before emergency medical technician arrival was difficult to calculate. Third, there were missing data on prehospital resuscitation variables in some patients, including EtCO2 and prehospital DC shock times. These data could provide additional information on the resuscitation status of the patients. Fourth, some patients had extremely poor hemodynamic status even under ECMO, making the diagnostic or intervention not feasible. This may have affected the estimation of the proportion of cardiogenic causes. Finally, our hospital is located in a densely populated area, and the prehospital transport time was relatively short (20-30 minutes), making our experiences more generalisable to city areas rather than rural areas.

\section{Conclusions}

In patients with OHCA receiving ECPR, a shockable rhythm at hospital arrival could predict favourable neurological outcomes more precisely than the initial shockable rhythm. The ECPR selection criteria should consider the rhythm at hospital arrival.

\section{Declarations}

\section{Ethical Approval and Consent to participate}

This research is approved by the ethics committee of National Taiwan University hospital (202109038RINB). The requirement for informed consent was waived because of the retrospective nature.

\section{Consent for publication}

This manuscript does not contain any data of individual person in any form.

\section{Availability of supporting data}


The datasets used and analysed during the current study are available from the corresponding author on reasonable request.

\section{Competing interests}

The authors declare that they have no conflicts of interest.

\section{Funding}

There is no sources of funding in the development of this study.

\section{Authors' contributions}

The authors, PIS, MST, WTC, CHW, WTC, HMM, WJC, and CHH, have no commercial associations or sources of support that might pose a conflict of interest, and we thus declare no conflicts of interest in connection with this paper.

\section{Acknowledgements}

Not applicable.

\section{References}

1. Kiguchi T, et al. Out-of-hospital cardiac arrest across the World: First report from the International Liaison Committee on Resuscitation (ILCOR). Resuscitation. 2020;152:39-49.

2. Gajarski RJ, et al. Cost-effectiveness analysis of alternative cooling strategies following cardiac arrest. SpringerPlus. 2015;4:427-7.

3. Huang $\mathrm{CH}$, et al. Association of hemodynamic variables with in-hospital mortality and favorable neurological outcomes in post-cardiac arrest care with targeted temperature management. Resuscitation. 2017;120:146-52.

4. Yan S, et al. The global survival rate among adult out-of-hospital cardiac arrest patients who received cardiopulmonary resuscitation: a systematic review and meta-analysis. Crit Care. 2020;24(1):61.

5. Berdowski J, et al. Importance of the first link: description and recognition of an out-of-hospital cardiac arrest in an emergency call. Circulation. 2009;119(15):2096-102.

6. DuBose JJ, et al. The AAST prospective Aortic Occlusion for Resuscitation in Trauma and Acute Care Surgery (AORTA) registry: Data on contemporary utilization and outcomes of aortic occlusion and resuscitative balloon occlusion of the aorta (REBOA). J Trauma Acute Care Surg. 2016;81(3):40919.

7. Kitamura T, et al. Public-Access Defibrillation and Out-of-Hospital Cardiac Arrest in Japan. N Engl J Med. 2016;375(17):1649-59.

8. Benjamin EJ, et al. Heart Disease and Stroke Statistics-2018 Update: A Report From the American Heart Association. Circulation. 2018;137(12):e67-492. 
9. Wong CX, et al., Epidemiology of Sudden Cardiac Death: Global and Regional Perspectives. Heart, Lung and Circulation, 2019. 28(1): p. 6-14.

10. Iwami T, et al. Effectiveness of bystander-initiated cardiac-only resuscitation for patients with out-ofhospital cardiac arrest. Circulation. 2007;116(25):2900-7.

11. Cha WC, et al. Regionalisation of out-of-hospital cardiac arrest care for patients without prehospital return of spontaneous circulation. Resuscitation. 2012;83(11):1338-42.

12. Ong ME, et al. Outcomes for out-of-hospital cardiac arrests across 7 countries in Asia: The Pan Asian Resuscitation Outcomes Study (PAROS). Resuscitation. 2015;96:100-8.

13. Gräsner JT, et al., EuReCa ONE-27 Nations, ONE Europe, ONE Registry: A prospective one month analysis of out-of-hospital cardiac arrest outcomes in 27 countries in Europe. Resuscitation, 2016. 105: p. 188-95.

14. Beyea MM, et al. Neurologic outcomes after extracorporeal membrane oxygenation assisted CPR for resuscitation of out-of-hospital cardiac arrest patients: A systematic review. Resuscitation. 2018;130:146-58.

15. Debaty G, et al. Prognostic factors for extracorporeal cardiopulmonary resuscitation recipients following out-of-hospital refractory cardiac arrest. A systematic review and meta-analysis. Resuscitation. 2017;112:1-10.

16. Patricio $D$, et al. Comparison of extracorporeal and conventional cardiopulmonary resuscitation: a retrospective propensity score matched study. Crit Care (London England). 2019;23(1):27-7.

17. Kim SJ, et al. Comparing extracorporeal cardiopulmonary resuscitation with conventional cardiopulmonary resuscitation: A meta-analysis. Resuscitation. 2016;103:106-16.

18. Ortega-Deballon I, et al. Extracorporeal resuscitation for refractory out-of-hospital cardiac arrest in adults: A systematic review of international practices and outcomes. Resuscitation. 2016;101:12-20.

19. Lamhaut $L$, et al. A Pre-Hospital Extracorporeal Cardio Pulmonary Resuscitation (ECPR) strategy for treatment of refractory out hospital cardiac arrest: An observational study and propensity analysis. Resuscitation. 2017;117:109-17.

20. Sakamoto T, et al. Extracorporeal cardiopulmonary resuscitation versus conventional cardiopulmonary resuscitation in adults with out-of-hospital cardiac arrest: A prospective observational study. Resuscitation. 2014;85(6):762-8.

21. Kawashima T, et al. Impact of first documented rhythm on cost-effectiveness of extracorporeal cardiopulmonary resuscitation. Resuscitation. 2019;140:74-80.

22. Panchal AR, et al., Part 3: Adult Basic and Advanced Life Support: 2020 American Heart Association Guidelines for Cardiopulmonary Resuscitation and Emergency Cardiovascular Care. 2020. 142(16_suppl_2): p. S366-S468.

23. Wang $\mathrm{CH}$, et al. Improved outcome of extracorporeal cardiopulmonary resuscitation for out-ofhospital cardiac arrest-a comparison with that for extracorporeal rescue for in-hospital cardiac arrest. Resuscitation. 2014;85(9):1219-24. 
24. Chang WT, et al. Optimal Arterial Blood Oxygen Tension in the Early Postresuscitation Phase of Extracorporeal Cardiopulmonary Resuscitation: A 15-Year Retrospective Observational Study. Crit Care Med. 2019;47(11):1549-56.

25. Lunz D, et al. Extracorporeal membrane oxygenation for refractory cardiac arrest: a retrospective multicenter study. Intensive Care Med. 2020;46(5):973-82.

26. Bougouin W, et al. Extracorporeal cardiopulmonary resuscitation in out-of-hospital cardiac arrest: a registry study. Eur Heart J. 2019;41(21):1961-71.

27. Bartos JA, et al. Improved Survival With Extracorporeal Cardiopulmonary Resuscitation Despite Progressive Metabolic Derangement Associated With Prolonged Resuscitation. Circulation. 2020;141(11):877-86.

28. de Graaf C, Beesems SG, Koster RW. Time of on-scene resuscitation in out of-hospital cardiac arrest patients transported without return of spontaneous circulation. Resuscitation. 2019;138:235-42.

29. Wengenmayer T, et al. Influence of low-flow time on survival after extracorporeal cardiopulmonary resuscitation (eCPR). Crit Care. 2017;21(1):157.

\section{Figures}

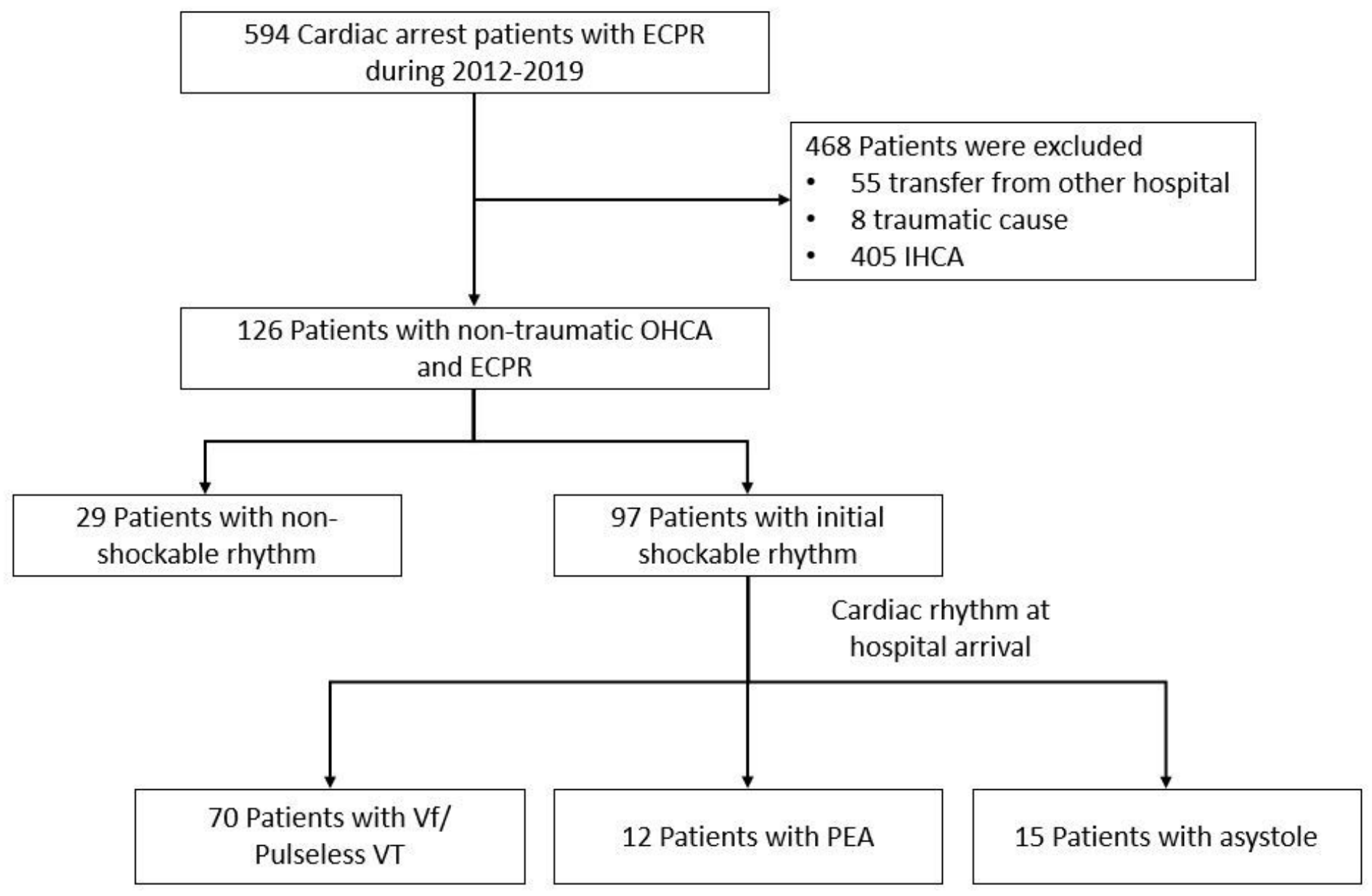


Figure 1

Patient enrolment.

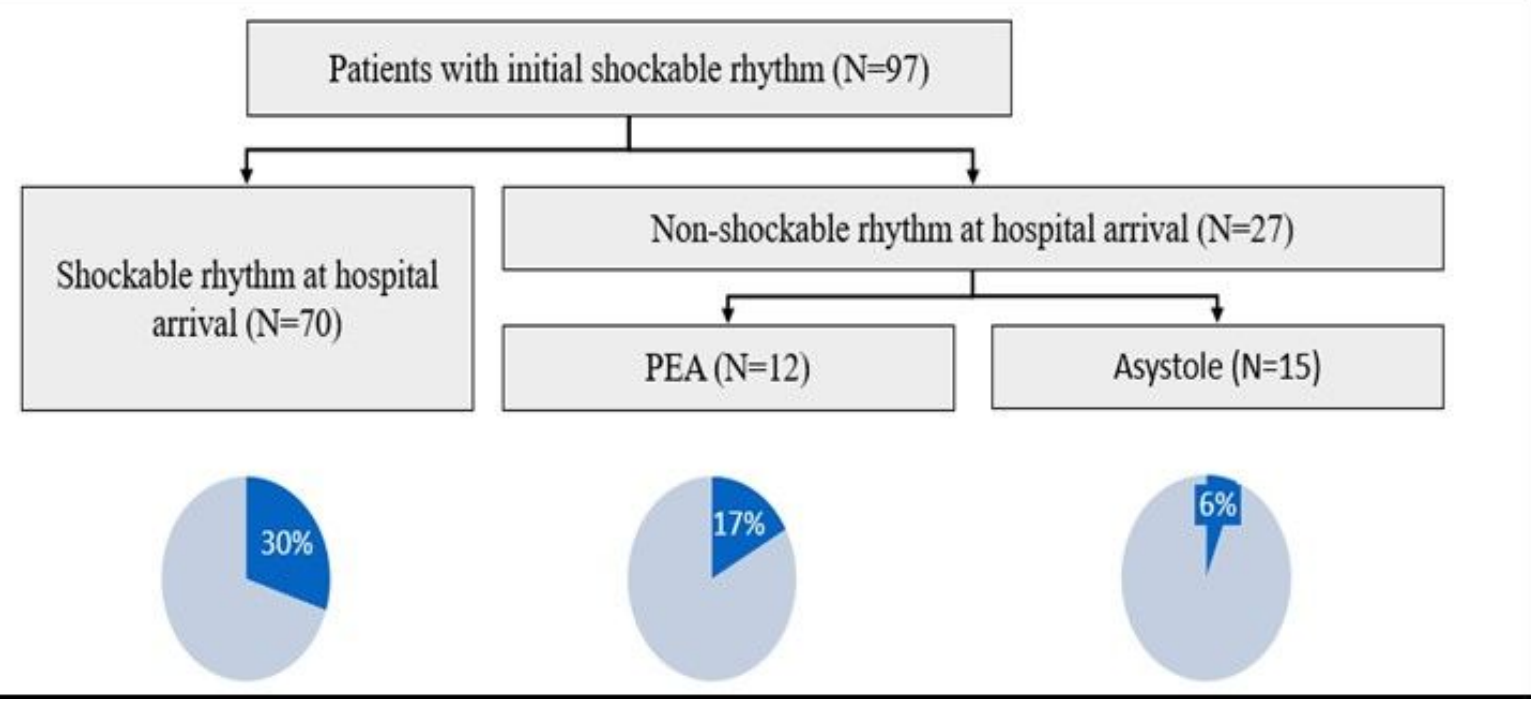

\section{Figure 2}

Favourable neurological outcome according to the cardiac rhythm at hospital arrival among patients with initial shockable rhythm.

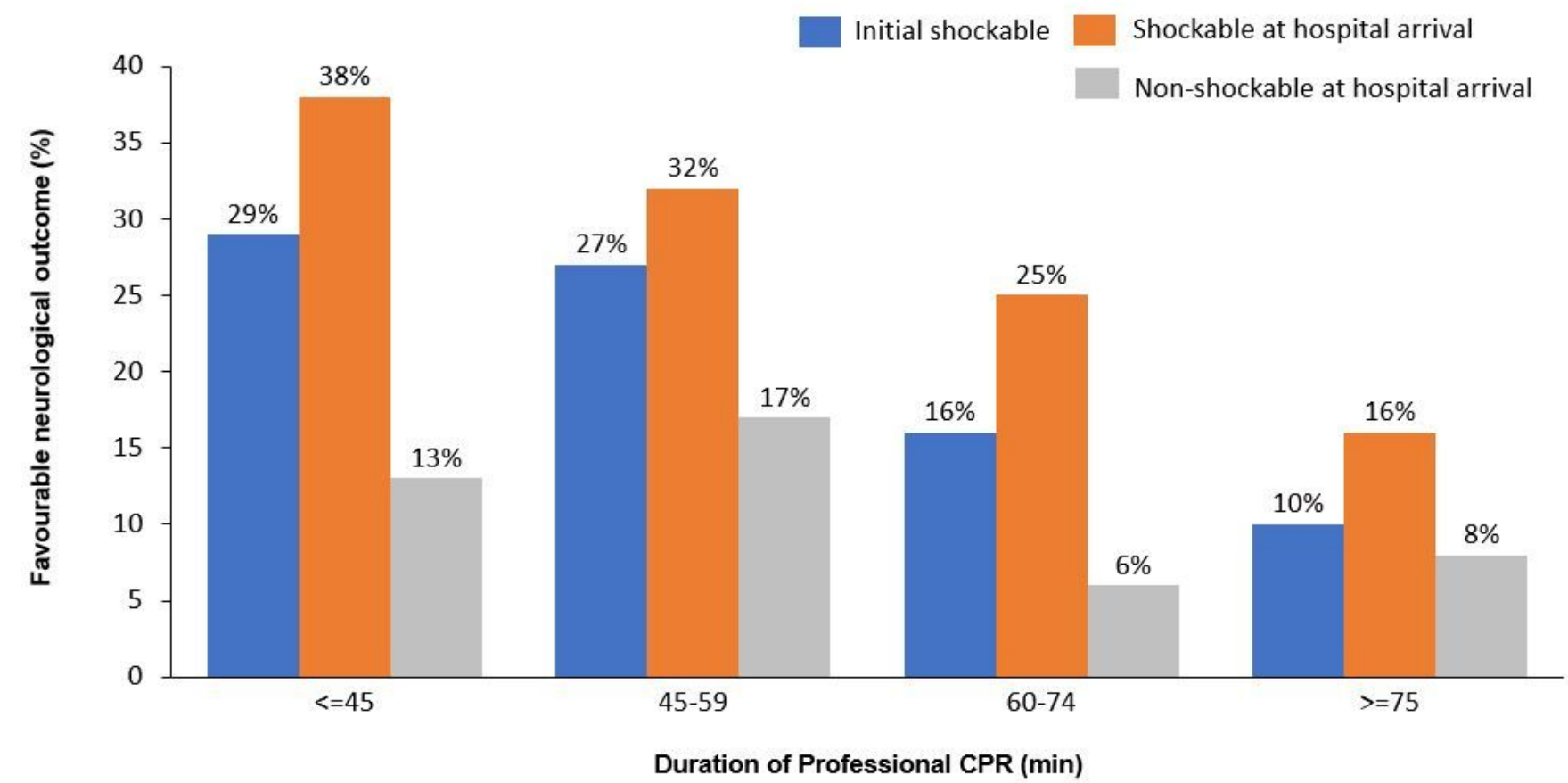

Figure 3

Percentage of favourable outcome according to the time of arrest-ECMO implementation among patients with initial shockable rhythm. Patients were further separated according to the rhythm at hospital arrival. 